\section{Years of Newborn Screening in Uruguay}

\author{
Cecilia Queijo' ${ }^{10}$, A. Lemes ${ }^{1}$ and G. Queiruga ${ }^{2}$
}

Journal of Inborn Errors of Metabolism \& Screening 2021, Volume 9: e20210008 DOI: https://doi.org/10.1590/2326-4594 JIEMS-2021-0008

\begin{abstract}
In the 1960s Guthrie conceived the idea of preventing congenital disease using dried blood spot samples on filter paper to detect them through biochemical tests and then be able to treat environmental factors in time to avoid the devastating effect of the diseases. Uruguay started in 1994 with the detection of congenital hypothyroidism in umbilical cord blood. In 2007 it was extended to Phenylketonuria and Congenital Adrenal Hyperplasia, starting with dried blood spot sample. In 2008, with the incorporation of Mass Spectrometry, a pilot program was started for the detection of aminoacidopathies, beta-oxidation defects and organic acidemias disorders. In the following years, the program expanded to more diseases, reaching a total of 25 disorders that could be detected, 5 of them are investigated on a mandatory basis and others in pilot program. During the 25 -year of experience, 974277 umbilical cord blood samples were analyzed and since 2007: 532684 dried blood spot samples. 613 true positive congenital disorders were identified. The coverage has been greater than $98 \%$ and the repetition rate for insufficient samples less than $1.9 \%$.
\end{abstract}

Keywords: Newborn screening, Congenital hypothyroidism, Cystic fibrosis, Congenital adrenal hyperplasia, Haemoglobinopathies, MCAD, Phenylketonuria.

\section{Introduction}

From the 60 s, worldwide, the implementation of strategies for the prevention of congenital diseases began. Although they do not present clinical symptoms at birth, there are biochemical tests that detect this disorders early. This allows to treat them in time and thus avoid its devastating effect such as malnutrition, mental retardation or death. Starting in the 1990s, the incorporation of tandem mass spectrometry (MS/ MS) for neonatal screening revolutionized diagnostic capacity by allowing multiple metabolites to be obtained from a single blood sample. It is at this stage that Latin America discreetly begins to incorporate this practice into Public Health.[1]

Historically, Uruguay has been characterized by developing public policies for the protection of children by promoting programs for the prevention of childhood diseases. In addition, it is a country with a low birth rate (approximately 45,000 births / year), which means that each child has an inestimable value for the future of our society.[2]

In this framework, on August 1, 1990, the clinical laboratory of the maternity of the Banco de Previsión Social (BPS), began the detection of Congenital Hypothyroidism $(\mathrm{CH})$ to its newborns (NB).
Since the clinical laboratory receives cord blood from its newborns for the study of congenital syphilis, this sample is used for TSH determination. The first case of $\mathrm{CH}$ was detected at 12 days of age, after analyzing 2800 samples. In 1994, after having detected 10 cases of $\mathrm{CH}$, the Ministerio de Salud Pública (MSP) established its detection mandatory for all newborns in the country (Decree 183/94).[3] It was quickly reached a coverage greater than $95 \%$ of the NB.

Therefore, the National Newborn Screening System (NNSS) in Uruguay, promoted by BPS, was a pioneer in the region, officially beginning in 1994 .

The purpose of this paper is to describe the development and the results of the NNSS from Uruguay since its implementation, 25 years ago.

\footnotetext{
${ }^{1}$ Banco de Prevision Social, Laboratorio de Pesquisa Neonatal, Montevideo, Uruguay.

${ }^{2}$ Consejo de la Facultad de Química, UdelaR, Montevideo, Uruguay.
}

Received january 28, 2021, and in revised form april 16, 2021. Accepted for publication april 19, 2021.

\section{Corresponding Author:}

Cecilia Queijo, Email: cqueijo@bps.gub.uy 


\section{Materials and Methods}

\section{Regulation}

The MSP, as the regulatory authority in health matters, is the one who establishes which congenital disorder is incorporated into the NNSS.

Over the years, BPS has worked to incorporate more conditions to be detected. Figure 1 shows the history and evolution of NNSS in Uruguay.

Nowadays, Newborn Screening Laboratory (NSL) include 25 detectable conditions. (Table 1)

From the regulatory point of view, the disorders detected are defined as mandatory (there is a regulatory decree that regulates them) and others are in a pilot plan.

During 2013, the MSP declares the Newborn Screening Laboratory (NSL) of BPS, as the National Reference Laboratory for the study of NB screening diseases. (Decree 325/013)

\section{Organization}

In the spirit of the National Integrated Health System (SNIS), in coordination with health providers trying to complement strengths and not duplicate efforts, various public and private institutions were integrated to coordinate actions to achieve the proper functioning of the NNSS (Figure 2).

The MSP as the government agency, provides the legislation for the development and growth of the NNSS.

Public and private health providers that have maternity ward, have the responsibility of taking the sample through their nursing staff, the quality of which is essential for an adequate and efficient diagnosis. They are in charge of confirmatory studies, follow-up and treatment of cases of positive screening for endocrinopathies and haemoglobinopathies.

The National Post Service is committed to transport all the samples in specially designed and prepaid envelopes from all maternity ward in the country to the NSL.

The NSL, which is part of the BPS, is the one that processes all the dried blood spot (DBS) samples and is responsible for the logistics of acquisition, storage and distribution of the material necessary to carry out the sample collection.
The CHLA and EP, through their staff distributed throughout the country, being responsible for the national immunization program, collaborate with the recall of patients either due to an altered result or an insufficient sample.[4]

The NNSS is fully consolidated within the SNIS and is based on three pillars:

National Scope: neonatal screening is a right of every child born in the country. The entire territory is reached through health providers who have maternity facilities, as well as home births carried out with the assistance of midwives.

Universal and free of charge: at the moment there is no charge for the population, which allows and ensures a universality of the service.

High coverage: since its beginning, the program obtained a large percentage of recruitment, greater than $98 \%$ of newborns.

\section{Population}

The NNSS's target population is all babies born in Uruguayan territory, without exceptions. Includes those born whose mother is not a resident of our country.

The retrospective indicator that compares the number of samples received in the NSL with the live births of the National Civil Identification System allows us to establish that the NNSS has coverage of more than $98 \%$ of all births. In Uruguay, all NBs receive an identification document number at the time of birth.

NB samples from public and private institutions are included, as well as the ones from home births.

\section{Sample Collection}

Since the beginning, in 1994, and depending on the geographic place of birth as well as the facilities for transportation, the sample of choice for the detection of $\mathrm{CH}$ was cord blood on filter paper or serum. Over the years, hospitals with the possibility of internally perform assay of TSH, began to do so, decentralizing this assay. Nowadays, only one third of the newborn population is tested in the NSL for this disease.[5]

In 2007, when other conditions were incorporated into the NNSS, the use of samples of whole blood obtained from DBS samples began. This samples are taken after 40 hours of the newborn's life and having been ingested protein food.

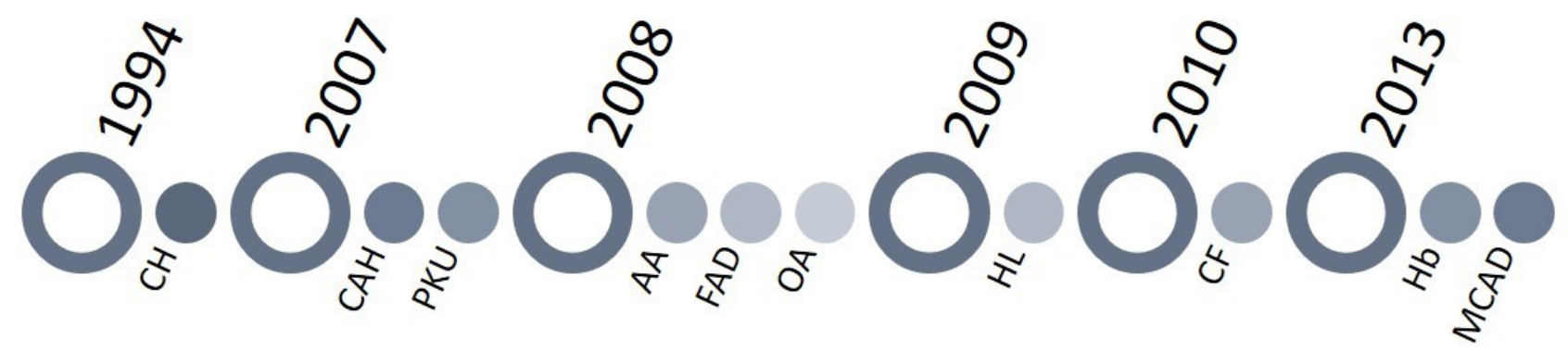

Figure 1. Evolution of the diseases incorporated to NNSS. CH: Congenital hypothyroidism; $\mathrm{CAH}$ : Congenital Adrenal Hyperplasia; PKU: Phenylketonuria; AA: amino acid defects; FAD: fatty acid defects; OA: organic acidemias; HL: Hearing loss; CF: Cystic fibrosis; Hb: hemobloginopathies; MCAD: medium chain Acil CoA dehydrogenase deficiency. 
Table 1. Disorders detected in the NNSS. The method, sample, biomarker and cut-off are detailed for each one.

\begin{tabular}{|c|c|c|c|c|c|c|}
\hline & DISORDER & & METHOD & SAMPLE & BIOMARKER & CUT-OFF \\
\hline \multirow{6}{*}{ MANDATORY } & Congenital hypothyroidism & $\mathrm{CH}$ & Fluoroimmunoassay AutoDELFIA & DBS & TSH & $9 \mathrm{uUl} / \mathrm{ml}$ \\
\hline & & & Fluoroimmunoassay AutoDELFIA & Cord DBS & TSH & $18 \mathrm{uUl} / \mathrm{ml}$ \\
\hline & & & ECLIA & Cord serum & $\mathrm{TSH}$ & $25 \mathrm{uUl} / \mathrm{ml}$ \\
\hline & Congenital adrenal hyperplasia & $\mathrm{CAH}$ & Fluoroimmunoassay AutoDELFIA & DBS & $\begin{array}{l}17-\mathrm{OH} \\
\text { progesterone }\end{array}$ & $5.5 \mathrm{ng} / \mathrm{ml}$ \\
\hline & Cystic Fibrosis & $\mathrm{FQ}$ & Fluoroimmunoassay AutoDELFIA & DBS & IRT & 59 ug/l \\
\hline & $\begin{array}{l}\text { Medium-chain acyl-CoA } \\
\text { dehydrogenase deficiency }\end{array}$ & MCADD & MS/MS & DBS & $\begin{array}{c}\text { C8 } \\
\text { C6 } \\
\text { C10:1 } \\
\text { C10 } \\
\text { C8/C2 } \\
\text { C8/C10 }\end{array}$ & $\begin{array}{c}0.31 \mathrm{umol} / \mathrm{l} \\
0.24 \mathrm{umol} / \mathrm{l} \\
0.35 \mathrm{umol} / \mathrm{l} \\
0.53 \mathrm{umol} / \mathrm{l} \\
0.02 \\
3.0\end{array}$ \\
\hline \multirow{17}{*}{$\begin{array}{c}\text { PILOT } \\
\text { PROGRAM }\end{array}$} & Maple syrup urine disease & MSUD & MS/MS & DBS & $\begin{array}{l}\text { Xleu } \\
\text { Val }\end{array}$ & $\begin{array}{l}313 \mathrm{umol} / / \\
216 \mathrm{umol} / \mathrm{l}\end{array}$ \\
\hline & Citrullinemia & CIT & MS/MS & DBS & Cit & 52 umol/l \\
\hline & Tyrosinemia & TYR & MS/MS & DBS & Tyr & $147.7 \mathrm{umol} / \mathrm{l}$ \\
\hline & Argnininemia & ARG & MS/MS & DBS & $\operatorname{Arg}$ & $18.5 \mathrm{umol} / \mathrm{l}$ \\
\hline & $\begin{array}{c}\text { Carnitine uptake defect/carnitine } \\
\text { transport defect }\end{array}$ & CUD & MS/MS & DBS & $\mathrm{CO}$ & $10.84 \mathrm{umol} / / \mathrm{l}$ \\
\hline & $\begin{array}{c}\text { Carnitine palmitoyltransferase type } \\
\text { I deficiency }\end{array}$ & CPT-1 & MS/MS & DBS & $\mathrm{C} 0 /(\mathrm{C} 16+\mathrm{C} 18)$ & 31.22 \\
\hline & $\begin{array}{l}\text { Long-chain L-3 hydroxyacyl-CoA } \\
\text { dehydrogenase deficiency }\end{array}$ & LCHAD & MS/MS & DBS & $\mathrm{C} 16 \mathrm{OH}$ & $0.14 \mathrm{umol} / \mathrm{l}$ \\
\hline & $\begin{array}{l}\text { Short-chain acyl-CoA } \\
\text { dehydrogenase deficiency }\end{array}$ & SCAD & MS/MS & DBS & C4 & $0.87 \mathrm{umol} / \mathrm{l}$ \\
\hline & Glutaric acidemia type I & GA I & MS/MS & DBS & C5DC & $0.36 \mathrm{umol} / \mathrm{l}$ \\
\hline & Isovaleric acidemia & IVA & MS/MS & DBS & $\begin{array}{c}\mathrm{C} 5 \\
\mathrm{C} 5 / \mathrm{C0} \\
\mathrm{C} 5 / \mathrm{C} 2 \\
\mathrm{C} 5 / \mathrm{C} 3\end{array}$ & $\begin{array}{c}0.41 \mathrm{umol} / \mathrm{I} \\
0.02 \\
0.03 \\
0.32\end{array}$ \\
\hline & Propionic acidemia & PA & MS/MS & DBS & $\begin{array}{c}\mathrm{C3} \\
\mathrm{C} 3 / \mathrm{C2}\end{array}$ & $\begin{array}{c}5.34 \mathrm{umol} / \mathrm{l} \\
0.35 \\
372\end{array}$ \\
\hline & Methylmalonic acidemia & Cbl/Mut & $\mathrm{MS} / \mathrm{MS}$ & DBS & C3/Met & $\begin{array}{l}3.12 \\
0.8\end{array}$ \\
\hline & 3-Hydroxy-3-methyglutaric aciduria & HMG & MS/MS & DBS & & \\
\hline & B-ketothiolase deficiency & BKT & MS/MS & DBS & & \\
\hline & $\begin{array}{l}\text { 3-Methylcrotonyl-CoA } \\
\text { carboxylase deficiency }\end{array}$ & 3-MCC & MS/MS & DBS & $\mathrm{C} 5 \mathrm{OH}$ & $0.59 \mathrm{umol} / \mathrm{l}$ \\
\hline & $\begin{array}{l}\text { 2-methylbutyryl-CoA } \\
\text { dehydrogenase deficiency }\end{array}$ & 2-MBG & MS/MS & DBS & & \\
\hline & 3-Methylglutaconic aciduria & 3MGA & MS/MS & DBS & & \\
\hline
\end{tabular}




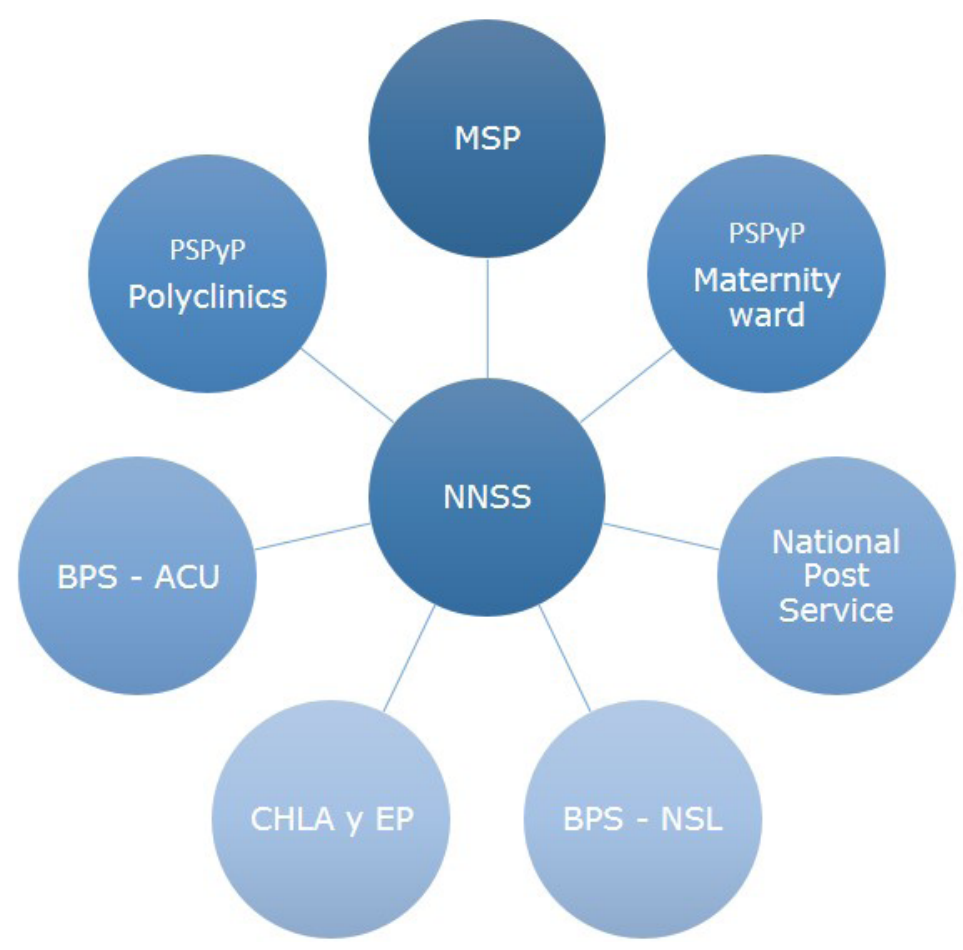

Figure 2. Scheme of National Public and Private Organizations that work together for the proper functioning of the NNSS. MSP: Ministerio de Salud Pública. PSPyP: Public and Private Health Providers. BPS: Banco de Previsión Social. NSL: Newborn Screening Laboratory. CHLA and EP: Comisión Honoraria para la Lucha Antituberculosa y Enfermedades Prevalentes. ACU: Ambulatory Care Unit.

This implied a logistical change and a lot of training for the different actors of the program, mainly the nursing staff responsible for taking this new sample.

The sample card has two areas: filter paper for the blood sample and another where the data of the newborn, the information of the mother and the center that attended the delivery and took the sample is shown. Data have been incorporated such as whether the child received a transfusion, whether he or the mother received medication, the type of feeding of the newborn and whether the mother is vegetarian, vegan or follows a special diet. All this information is critical for the subsequent interpretation of results.

All preterm NBs (gestational age less than 37 weeks and / or birth weight less than $2,500 \mathrm{~g}$ ) or twins, must repeat the sampling at 20 days of life. [6] It is the health provider's responsibility to comply with this directive.

The heel blood sample is taken from all newborns prior to hospital discharge, in order to ensure that all children with institutionalized births are included.

\section{Analytical methods}

The NNSS has mandatory studies included in the National Health Care Plan (PIAS) as well as others in a pilot plan, thus completing a panel of 25 conditions, as detailed in Table 1 .

Throughout these 25 years, technology and local suppliers have changed and the NSL has adapted to obtain the best possible results.

\section{Congenital hypothyroidism}

At present, the NSL conducts the CH screening of only a part of the samples, since approximately $70 \%$ of them are analyzed in the institutions where the child is born.

As detailed in Table 1, three types of samples coexist: DBS, cord blood on filter paper, and cord blood serum. For any of them, the working algorithm implies that, when a TSH determination is higher than the cut-off ( $0.5 \%$ of the samples received), all the TSH is repeated in the sample of DBS (sample received for the other conditions and taken after the 40 hours of life). If this result is also higher than the cut off, urgent confirmation is requested in venous blood, in the center where the delivery was performed. If the TSH value in the first sample is greater than $25 \mathrm{uIU} / \mathrm{ml}$ for cord DBS or greater than $50 \mathrm{uIU} / \mathrm{ml}$ for cord serum, confirmation in venous blood is urgently requested without waiting for the result of the DBS.[5,7]

\section{Congenital adrenal hyperplasia}

$\mathrm{CAH}$ screening is carried out by determining $17-\mathrm{OH}$ progesterone, detecting exclusively deficiency of the enzyme 21-hydroxylase. This deficiency corresponds to $90-95 \%$ of cases of CAH. With an altered result, a new sample of DBS is requested ( $2 \%$ of the samples processed). In a positive case, the confirmatory studies must be carried out by the hospital where the baby was born. It is important to remember that this biomarker varies with gestational age, therefore the cut-off changes according to this parameter. The one indicated in Table 1, corresponds to term NBs. [8] 
It is also important to remember that if the child or the mother has received corticosteroids (very commonly used for fetus lung maturation) at least 15 days before delivery, the sample must be repeated after 20 days of life, to avoid false negatives.

\section{Cystic fibrosis}

For $\mathrm{CF}$, the screening is established by determining immunoreactive trypsin (IRT). When IRT is increased, the pancreatitis-associated protein (PAP) is measured on the same sample. Simultaneously a second sample is requested (less than $1 \%$ of the samples processed). According to the profiles obtained in the first and second sample (30\% of the second samples remained elevated), a sweat test is performed as a confirmatory study and a subsequent genetic study is performed in the NSL (panel of our most prevalent mutations).[7]

\section{Phenylketonuria / MCADD / Expanded screening}

The acylcarnitine and amino acid profile is determined by tandem mass spectrometry (MS/MS), carried out in two ABSciex API 3200. The Expanded Screening (ES) is performed by applying tandem mass spectrometry and provides biomarkers for 21 different conditions among which we identify: PKU, HPA and MCADD. All this, through a multiplex technology that provides a lot of information at a low cost, being the challenge the interpretation of the results.

With an altered result for any of the defined biomarkers, a second DBS is requested, with the exception of the marker for GA $\mathrm{I}$, which is immediately requested urine sample for confirmatory study as well as a second DBS.[9-13] If the profile of organic acids and / or the profile of acylcarnitine is altered again, the NB is urgently referred to the medical team of inborn errors of metabolism (IEM).

\section{Haemoglobinopathies}

HPLC-CE is used for haemoglobinopathies. This methodology is based on the separation of the different hemoglobin by cation exchange chromatography, allowing the detection of hemoglobin with structural variants. In turn, it provides semi-quantitative information, expressing the concentration percentage of the different hemoglobin. This allows detecting major thalassemia or double heterozygous carriers of thalassemia associated with structural hemoglobin.[14]

\section{Diagnosis, Monitoring and Treatment}

All positive cases are reported to the National Registry of Congenital Defects and Rare Diseases (RNDCER) of the Ministry of Public Health for its epidemiological control and surveillance. [15]

Patients with altered newborn screening results are referred to their health provider if it corresponds to a diagnosis of $\mathrm{CH}$ or HAC (Endocrinopathies) as well as haemoglobinopathies.
For the rest of the disorders detected, they are referred to the Ambulatory Care Unit (ACU) of the BPS.[2] In this case, all confirmatory studies, drugs, medical food (special formulas) are provided by BPS at no cost to the user.

\section{Results}

\section{Sample quality}

The quality of the sample continues to be one of the key stages in the neonatal screening process. The sampling is decentralized; it is carried out in each hospital in the country. This means that the quality of the same has great variability directly influencing the time to reach the final result. Insufficient / unsatisfactory samples are not suitable samples to be processed, so the responsible health provider is immediately informed for their repetition. Nowadays, insufficient / unsatisfactory samples range between 0.8 and $1.9 \%$ of the total samples received.

\section{Cases detected}

The average turnaround time for reporting results, once the sample has been entered into the laboratory, are: 2 days for 17$\mathrm{OH}$ progesterone, IRT and TSH and hemoglobin profile and 5 days for PKU, MCADD and ES.

Between 1994 and December 2019, 974277 cord blood samples were processed, finding 465 cases of $\mathrm{CH}$. The incidence for this disease in our country is 1:2095 newborns. As is known, $\mathrm{CH}$ is one of the most frequent causes of mental retardation. Fortunately in Uruguay, since the beginning of the universal screening for this disease, neonatal cases have stopped being seen.

From 2007 to 2018, 532684 DBS samples have been processed for the rest of the NNSS conditions. Table 2 shows the number of cases detected by disorder as well as the incidences calculated for our country.

It is worth remembering at this point that the national program includes a group of mandatory studies by decree and another group in the format of a pilot plan that, although all samples are processed for these markers, only those with altered results are reported.

Among the cases detected by the ES, the following conditions were confirmed: methylmalonic acidemia, glutaric acidemia type I, 3-methylcrotonyl-CoA carboxylase deficiency, primary carnitine deficiency, short-chain Acyl-CoA dehydrogenase deficiency, tetrahydrobiopterin deficiency (BH4), cobalamin $\mathrm{C}$ deficiency, and also the detection of maternal vitamin B12 deficiency leading to secondary neonatal methylmalonic acidemia.

Considering the disorders that have been detected in BPS, its confirmation is reached, on average, at 2 months for CF, 21 days for PKU and 30 days for MCADD.

As is described in other programs, we have detected false positives (Table 3) and false negatives cases for ES. Table 1 specifies the cut-off for the different biomarkers. 
Table 2. Number of cases and incidence of the disorders detected in the NNSS.

\begin{tabular}{lcc}
\hline DISORDER & $\mathbf{N}^{\circ}$ CASES & INCIDENCE \\
\hline CH & 465 & $1: 2095$ \\
PKU & 26 & $1: 20488$ \\
HPA & 15 & $1: 35512$ \\
CAH & 32 & $1: 16646$ \\
CF & 46 & $1: 9414$ \\
MCADD & 5 & $1: 96492$ \\
Haemoglobinopathies & 9 & $1: 31815$ \\
Expanded Screening & 15 & $1: 32164$ \\
Total & 613 & \\
\hline
\end{tabular}

$\mathrm{CH}$ : Congenital hypothyroidism; PKU: Phenylketunuria; HPA: Hyperphenylalaninemia; CF: Cystic Fibrosis; MCADD: Medium-chain acyl-CoA dehydrogenase deficiency; $\mathrm{CAH}$ : Congenital adrenal hyperplasia.

Table 3. Cases detected as false positives and the causes.

\begin{tabular}{ll}
\hline Altered biomarker & \multicolumn{1}{c}{ Causes } \\
\hline Increased tyrosine & Preterm NB \\
& Term NB with very early incorporation of cow's milk. Generally families from critical context. \\
Low C0 & Low-weight premature infants receiving PF. \\
& Term NBs who require prolonged PF because surgery f or example. \\
Increased $\mathrm{C5}$ & Mother receiving antibiotics for urinary infection during the last trimester of pregnancy. \\
Increased $\mathrm{Xleu}$ & Normal newborn urinary OA \\
Increased $\mathrm{C} 5 \mathrm{OH}$ & Increased plasma hydroxyproline \\
\hline
\end{tabular}

C0: free carnitine. C3: propionylcarnitine. C5: isovalerylcarnitine/2-methyl butirylcarnitine. Xleu: leucine/isoleucine/hydroxyproline. C5OH: hydroxyisovalerlcarnitine. PF: parenteral feeding. OA: organic acids. NB: newborn.

Among the false negatives we have 2 cases of $\mathrm{CF}, 1$ propionic acidemia, 1 SCAD, 1 tyrosinemia type I, 1 glutaric acidemia type I, 1 argininemia and 1 PKU.

Regarding $\mathrm{CH}, \mathrm{CAH}$ and Haemoglobinopathies we do not have data to report because we did not carry out the confirmatory test.

\section{Current Strategy}

These years have allowed us to evaluate different strategies to improve the NNSS, incorporate new technologies and increase the training of the professionals involved.

Table 4 summarizes by disorder the scope that the BPS covers in terms of the screening, diagnosis and follow-up of the detected patients, thus outlining the current strategy of the NNSS.

\section{Discussion}

It has been internationally proven that NBS programs are a very effective and efficient public health tool in secondary prevention to improve the prognosis and quality of life of patients with any of the conditions included in the program. In addition, NBS programs can bring significant cost-benefit advantages for the newborns, their families as well as for public healthcare systems. (16).
For Uruguay, which has a declining birth rate, the life and quality of life of each child constitutes a valuable human capital for the future development of the country.

During the last 25 years, a total of 613 cases have been detected, changing the natural history of diseases.

Regarding the coverage of the NNSS, collecting the sample at 40 hours of life after having received protein feeding and before hospital discharge, has allowed a high percentage of coverage from the beginning. Added to this is the commitment of midwives who assist deliver at home by choice of families (a practice that we see is rising over time) who take the newborn sample and personally transport them to the NSL.

The time elapsed between the reception of the sample in the NSL and the incorporation of the result into the computer system is critical. The communication of positive screening to the corresponding clinical team is done immediately.

As shown in Figure 1, the greatest advances in the incorporation of conditions to be screened occurred in 2007. The NSL, convinced of the benefits of the NBS, is in dialogue with the different authorities of the MSP in order to arrive at the mandatory inclusion by decree, to the study of ES and haemoglobinopathies (pilot plan at present).

$\mathrm{CH}$ continues to be the disease with the highest incidence (1:2095 NB). Based on the prevalence, the ease of diagnosis, the simplicity of the treatment and the clear individual benefit of the 
Table 4. Development of the benefits provided in the BPS for each disorder or group of disorders.

\begin{tabular}{lccccc}
\hline Disorder & NBS & $\mathbf{2}^{\circ}$ tier test & Confirmatory test & Molecular definition & Follow-up \\
\hline CH & Yes partial & No & Yes partial & No & No \\
PKU & Yes & No & Yes & Yes & Yes \\
HPA & Yes & No & Yes & No & No \\
CAH & Yes & No & No & Yes $*$ & Yes \\
CF & Yes & Yes PAP & Yes & Yes & Yes \\
MCADD & Yes & No & Yes & Yes & Yes \\
Aminoacidopathies & Yes & No & Yes & Yes & Yes \\
Beta-oxidation disorders & Yes & No & Yes & Yes partial & No \\
Organic acidemias & Yes & No & Yes partial & Yes \\
Haemoglobinopathies & Yes & No & &
\end{tabular}

*Panel with the most prevalent mutations done in NSL, if the result is not conclusive, complete CFTR gene sequencing is performed externally. *** performed externally to the NSL

diagnosis, it is undoubtedly the first disease of choice to incorporate into a NBS program. It is noteworthy that since the diagnosis, follow-up and treatment of these patients are not centralized in BPS, it is difficult to know the total confirmed cases. This is why we reported in this work what is exclusively studied in BPS, so, it does not reflect the amount of total $\mathrm{CH}$ cases in Uruguay.

The incidences of the diseases investigated mandatory are comparable to those published by other countries, as well as organizational structure, biomarkers chosen to define altered screening and work algorithms.[17-23]

Although the conditions investigated in the pilot plan are infrequent, if we consider them in their entirely (24 disorders, not including $\mathrm{CH}$ ) in the period in which all were screened (2013 - 2018), the incidence is 1:3579. For our country, where 37,448 children were born during 2019 , this implies the lives of approximately 11 Uruguayans, vital capital for our growth.

With regard to insufficient/unsatisfactory samples, work continues to get this indicator lower. For this, and except the last year due to pandemic, training workshops are held in different parts of the country. A point that is reinforced during the workshops is the importance of each person role, mostly at the time of sampling, where quality control of the sample should be done immediately.

The false negative cases of the newborn screening identified for ES, are 6. All were identified by symptoms or signs of their underlying disease, except for one patient with SCAD, who was studied with ES and urinary organic acids at 2 years of age due to developmental delay.

The rest of the patients correspond to: a case of type 1 tyrosinemia identified at 9 months of life due to hepatomegaly that ultrasound showed multiple nodules, had decreased prothrombin time, and very high alpha-fetoprotein $(230000 \mathrm{ng} / \mathrm{ml}$ for a normal value less than $10 \mathrm{ng} / \mathrm{ml}$ ); a case of low excretory glutaric aciduria who was admitted due to an acute encephalopathic crisis at 10 months of age, when the qualitative profile of urinary organic acids showed very little excretion of 3-hydroxyglutaric acid without glutaric acid and DBS acylcarnitine profile without increased glutarylcarnitine; a case of classic PKU with an abnormal NBS amino acid profile that was not identified in the NSL until
8 months after being studied for West syndrome; a case of argininemia with a normal neonatal arginine value in newborn screening that was studied because spastic paraparesis at the age of 4 years, had an organic acid profile with a slight increase in orotic acid and the amino acid profile of ES with an increase in arginine; one case of methylmalonic acidemia, the patient was admitted at 12 months due to failure to gain weight, detecting sustained metabolic acidosis with an increased anion gap and at that time, both the urinary organic acid profile and the acylcarnitine profile in the blood were consistent with said acidemia and the NBS had been normal; one case of propionic acidemia, the patient was admitted at 9 months of age due to the onset of abnormal movements in the course of an respiratory infectious disease with fever and at that time, both the urinary organic acid profile and the acylcarnitine profile in the blood were consistent with said acidemia and the NBS result had been normal.

All these cases led to a review of the processes that involved cut-off adjustments, a review of primary and secondary condition biomarkers, as well as a review of results by two different professionals.

As the diseases detected by ES have genetic bases, all the siblings of each confirmed case are studied. The older brother of a patient with MCAD was detected who was also included in the follow-up and treatment in the AU of BPS. In this sense, the NBS of the first child in four couples, who was positive for PKU, allowed the early diagnosis for the second child in all four cases.

With regard to maternal vitamin B12 deficiency, the studies of children detected by NBS (vitamin B12 in blood, folic acid in blood, homocytheinemia and organic acids in urine), are covered by the NNSS, but not those corresponding to their mothers who has to be study by their own healthcare provider.

To date, no patient detected by ES has died. In all detected cases, there is a change in the natural history of the disease.

The identification of cases of maternal diseases detected through the study of the newborn is described.[24] All our positive cases corresponded to profiles due to newborn disease.

With the exception of two cases, no patient had symptoms at the time of first contact with the IEM clinical team at the AU. Both cases corresponded to hyperphenylalaninemia later 
confirmed as $\mathrm{BH} 4$ deficiency, who presented mild generalized hypertonia and irritability, and a patient with cobalamin C deficiency, who had slight axial hypotonia.

Given our low population and birth rate in our country, the MSP is working on the generation of Reference Centers for different groups of rare conditions to have teams with experience in them. In this context, the NSL aspires, in addition to continuing to be the Reference Laboratory for Newborn Screening, to be a National Reference Laboratory for the Diagnosis of IEM. For this, we have the equipment and trained professionals to carry out the diagnostic confirmations of the conditions screened (with the exception of the $\mathrm{CAH}$, carried out by the health provider), the detection of the mutations that cause the disease as well as other techniques for the study of IEM not included in the NNSS. We plan to continue growing in this line to support medical teams in the difficult task of diagnosing these rare diseases.

\section{Conclusions}

We can conclude that the NNSS in Uruguay, which began formally in 1994, has gone through different stages, always progressing in terms of the organization of the system, as well as the progressive inclusion of conditions to be studied. The newborn screening makes an important difference in the prognosis of these diseases. Convinced of this, the NSL team requests the incorporation of the ES (pilot plan) to the current mandatory panel. Weaknesses in the NNSS process to improve are recognized, such as the quality of the DBS samples and the response times of the results for ES. We still have pending the evaluation of many other indicators, which we believe will give us the necessary information to continue optimizing the strategy of the National Newborn Screening.

In Uruguay, the impact of the work carried out in newborn screening in 25 years is very clear: the natural history of the disease has changed in 613 detected cases, of diseases with a prognosis as devastating as it is fatal.

\section{Declaration of Conflicting Interests}

The authors declare no conflict of interest.

\section{References}

1. Therrell BL, Padilla CD, Loeber JG, et al. Current status of newborn screening worldwide: 2015. Semin Perinatol. 2015;39(3):171-187. doi:10.1053/j.semperi.2015.03.002

2. Queiruga G, Lemes A, Ferolla C, Machado M, Queijo C, Machado P, Parallada G. Pesquisa Neonatal: lo que puede prevenir una gota de sangre. Montevideo: Editorial Centro de Estudios en Seguridad Social, Salud y Administración, 2010 .
3. Queiruga G. Detección sistemática de hipotiroidismo congénito a todos los recién nacidos de Uruguay. Rev Asociación Quím Farm Uruguay. 1994; 7-11.

4. Queiruga G, Queijo C, Lemes A, Machado M, Garlo P. Sistema Nacional de Pesquisa Neonatal en Uruguay. Mem Inst Investig Cienc Salud. 2011;9(2):72-77

5. Queiruga G, Machado M, Lemes B, et al. Congenital hipothyroidism: 18 years of program in Uruguay. Rev Invest Clin. 2009;61(Suppl 1):79.

6. Miller J, Tuerck J, Awad K, et al. Newborn Screening Guidelines for Premature and/or Sick Newborns. Proposed Guideline. I/LA31-P. Wayne, US: NCCLS; 2009.

7. Lemes A, Queijo C, Garlo P, Machado M, Queiruga G. Pesquisa neonatal. Arch Pediatr Urug. 2012;83(1):40-44. http://www.scielo.edu.uy/pdf/adp/v83n1/v83n1a09.pdf

8. Garlo P, Machado M, Queijo C, Corbo L, Franca F, González F, Lemes A, Queiruga G. 17-hydroxyprogesterone cut off evaluation for the congenital adrenal hyperplasia screening. Rev Invest Clin. 2009;61(Suppl 1):81.

9. Chace DH. Mass spectrometry in the clinical laboratory. Chem Rev. 2001;101(2):445-77. doi:10.1021/cr990077+

10. Queijo C, Machado M, Franca F, Corbo L, González F, Lemes A, Queiruga G. Pilot Programe for newborn screening using mass spectrometry in Uruguay. Rev Invest Clin. 2009;61(Suppl 1):90.

11. Queijo C, Lemes A, Machado M, Garlo P, González F, Franca K, et al. Newborn screening of medium-chain acylCoA dehydrogenase deficiency in Uruguay. Acta Bioquim Clin Latinam. 2011;45(1):87-93.

12. Jones PM, Bennett MJ. The changing face of newborn screening: diagnosis of inborn errors of metabolism by tandem mass spectrometry. Clin Chim Acta. 2002;324(12):121-128. doi:10.1016/s0009-8981(02)00238-3

13. La Marca G. Mass spectrometry in clinical chemistry: the case of newborn screening. J Pharm Biomed Anal. 2014;101:174-82. doi:10.1016/j.jpba.2014.03.047.

14. Audicio P, Segobia B, Queijo C, Queiruga G. Primeros resultados del Plan Piloto de Pesquisa Neonatal de Hemoglobinopatías en Uruguay. Acta Bioquím Clín Latinoam. 2017;51(2):243-248. https://www.redalyc.org/ pdf/535/53552508010.pdf

15. Larrandaburu M, Vianna FLS, Griot K, et al. Rare Diseases in Uruguay: Focus on Infants with Abnormal Newborn Screening. J Inborn Errors Metab Screen. 2019;7: e20190002. doi:10.1590/2326-4594-JIEMS-2019-0002

16. Bennett MJ. Newborn screening for metabolic diseases: saving children's lives and improving outcomes. Clin Biochem. 2014;47(9):693-694. doi:10.1016/j. clinbiochem.2014.05.010 
17. La Marca G, Malvagia S, Casetta B, Pasquini E, Donati MA, Zammarchi E. Progress in expanded newborn screening for metabolic conditions by LC-MS/MS in Tuscany: update on methods to reduce false tests. J Inherit Metab Dis. 2008;31(Suppl 2):S395-S404. doi:10.1007/s10545008-0965-Z

18. Vilarinho L, Rocha H, Sousa C, Marcão A, Fonseca H, Bogas M, Osório RV. Four years of expanded newborn screening in Portugal with tandem mass spectrometry. J Inherit Metab Dis. 2010;33(Suppl 3):S133-S138. doi:10.1007/ s10545-010-9048-Z

19. Loukas YL, Soumelas GS, Dotsikas Y, Georgiou V, Molou E, Thodi G, Boutsini M, Biti S, Papadopoulos K. Expanded newborn screening in Greece: 30 months of experience. $J$ Inherit Metab Dis. 2010;33(Suppl 3):S341-S348. doi:10.1007/ s10545-010-9181-8

20. Lund AM, Hougaard DM, Simonsen H, et al. Biochemical screening of 504,049 newborns in Denmark, the Faroe Islands and Greenland - experience and development of a routine program for expanded newborn screening. Mol Genet Metab. 2012;107(3):281-293. doi:10.1016/j. ymgme.2012.06.006

21. Lindner M, Gramer G, Haege G, et al. Efficacy and outcome of expanded newborn screening for metabolic diseases-report of 10 years from South-West Germany. Orphanet J Rare Dis. 2011;20(6):44. doi:10.1186/1750-1172-6-44

22. Castiñeras DE, Couce ML, Marin JL, González-Lamuño $\mathrm{D}$, Rocha H. Newborn screening for metabolic disorders in Spain and worldwide. An Pediatr (Barc). 2019;91(2):128. e1-128.e14. doi:10.1016/j.anpedi.2019.05.007

23. Sánchez Pintos P, Cocho de Juan JA, et al. Evaluación y perspectiva de 20 años de cribado neonatal en Galicia. Resultados del programa. Rev Esp Salud Publica. 2020;16(94):e202012161.

24. Grünert SC, Stucki M, Morscher RJ, et al. 3-methylcrotonylCoA carboxylase deficiency: Clinical, biochemical, enzymatic and molecular studies in 88 individuals. Orphanet J Rare Dis. 2012;7:31. doi:10.1186/1750-1172-7-31 